\title{
Hypoglycemic Effects of Analog Rice Based from Arrowroot (Marantha arundinacea $L$.) and Cowpea (Vigna unguiculata $L$.) on Blood Sugar Level and Pancreas Histopathology of Diabetic Rat
}

\author{
Mariska Pricilla*, Efendi Oulan Gustav Hakim Nata Buana \\ Nutrition and Food Technology Department, Surya University, Tangerang, Banten, Indonesia
}

\begin{abstract}
Diabetes mellitus is the third largest cause of death in Indonesia and $90 \%$ of the cases are diabetes mellitus type 2. Diabetes mellitus type 2 can be prevented and controlled by healthy lifestyle, such as consumption of foods with low glycemic index. Indonesia has high dependence on white rice as staple food, while it is relatively high in glycemic index. One alternative to overcome this problem is analog rice from low glycemic index raw materials such as arrowroot and cowpea. The study was in vivo assay using nested design to examine the hypoglycemic properties of analog rice. The analog rice physical properties analysis results showed that all analog rice formulations were acceptable, therefore selected analog rice were the formulation with the highest and lowest arrowroot levels (A1B1C3 and A4B1C3 formulations). The chemical properties analysis results showed that the rice was high in dietary fiber, which are $17.33 \%(\mathrm{w} / \mathrm{w})$ and $21.30 \%(\mathrm{w} / \mathrm{w})$. The glycemic index value of analog rice is 39.40 and 37.12 . Analog rice had hypoglycemic effect on rat blood sugar by significantly reducing blood sugar for 21 days, which were $18.97 \%$ and $25.50 \%$. Analog rice supplementation for 21 days in rats could also improve the pancreatic beta cell profile.
\end{abstract}

Keywords: Analog rice; Arrowroot; Cowpea; Hypoglycemic; Pancreas histopathology

\section{INTRODUCTION}

According to data from the International Diabetes Federation, there are approximately 415 million diabetics worldwide. This number is expected to increase by up to 5 times in 2040. Indonesia itself is a country with the seventh highest diabetes sufferer in the world. According to the International Diabetes Federation (2018), diabetics in Indonesia are $6.9 \%$ of the total population in Indonesia. According to the Ministry of Health of the Republic of Indonesia, in 2013 patients categorized as potentially having diabetes were as much as $66.5 \%$. $90 \%$ of them are type 2 diabetics. Type 2 diabetes can be prevented and controlled with a healthy lifestyle, one of which is to consume low glycemic index foods.

Indonesia has a high dependency on white rice which has a high glycemic index. One alternative to rice is analog rice which is made with low glycemic indexed raw materials. One of the ingredients with a low glycemic index of arrowroot tubers has a glycemic index of 14 [1]. Besides, arrowroot tubers also contain watersoluble polysaccharides and food fiber that can be hypoglycemic. Arrowroot tubers are easily cultivated in Indonesia and the Ministry of Agriculture of the Republic of Indonesia has declared the arrowroot crop as one of the food commodities that have priority to be cultivated. Analog rice can also be added to protein sources from cowpea.

Arrowroot tubers and cowpea have the potential to reduce the risk of diabetes but have not been maximally utilized in the community. Therefore, arrowroot tubers and cowpea can be used as analog rice raw material as a choice of rice consumption as a staple food that is hypoglycemic. It is hoped that analog rice which is low in glycemic index and high in food fiber and water-soluble polysaccharides can reduce the risk of developing type 2 diabetes.

\section{MATERIALS AND METHODS}

Arrowroot (Marantha arundinaceae) obtained from Bojonegoro and black-eyed peas (Vigna unguiculata) obtained from Tangerang was the main material. Healthy male Sprague-Dawley rats weighed 250. $300 \mathrm{~g}$ more than 2 months old obtained from Faculty of Veterinary Medicine, Bogor Agricultural University. Other materials were IR 64 rice, alloxan monohydrate, glucose, glibenclamide, formalin, neoprene, methanol, phosphate buffer, insulin monoclonal antibody, DEPS, canada balsam, and standard feed.

Correspondence to: Mariska Pricilla, Nutrition and Food Technology, Surya University, Jelambar Street TPI I PC/3, North Jakarta, DKI Jakarta, 14450, Indonesia, Tel: +62 8193212 8668; E-mail: marispricilla@gmail.com

Received: November 26, 2019, Accepted: January 22, 2020, Published: January 29, 2020

Citation: Pricilla M, Buana EOGHN (2020) Hypoglycemic Effects of Analog Rice Based from Arrowroot (Marantha arundinacea L.) and Cowpea (Vigna unguiculata L.) on Blood Sugar Level and Pancreas Histopathology of Diabetic Rat. J Diabetes Metab 11:840. doi: 10.35248/2155-6156.20.11.840.

Copyright: (C) 2020 Pricilla M, et al. This is an open-access article distributed under the terms of the Creative Commons Attribution License, which permits unrestricted use, distribution, and reproduction in any medium, provided the original author and source are credited. 


\section{Preparation of products}

Arrowroot flour preparation: Arrowroot was peeled, cleanly washed, sliced, dried at $90^{\circ} \mathrm{C}$ for 10 hours, and sifted.

Black-eyed peas flour preparation: Black-eyed peas were cleanly washed, soaked in $0.05 \mathrm{M} \mathrm{Na}_{2} \mathrm{CO}_{3}$ solution for $24 \mathrm{~h}$, dried at $90^{\circ} \mathrm{C}$ for 6 hours, and sifted.

Analog rice preparation: Analog rice was prepared from arrowroot flour and black-eyed peas flour, added with CMC or sodium alginate and water. After mixed, the mixture was heated until gelatinization and formed into rice shape. The granule was dried at $90^{\circ} \mathrm{C}$ for 15 minutes.

Animal testing methods: The study was approved by Surya University Research Institute and Community Service, Indonesia in November 2018-January 2019. Sprague-dawley rats were caged with $2-3$ rats in each cage in conditioned rooms $\left(30-32^{\circ} \mathrm{C}, 60\right.$ $65 \%$ relative humidity, $12 \mathrm{~h}$ light/dark cycles). Water and diet were available ad libitum during experiments. Twenty five Spraguedawley rats were randomly divided into 5 groups, 5 rats each. All groups were diabetic induced rats, respectively supplemented with glibenclamide, CMC-Na, IR 64 rice, and 2 formulations of analog rice. Rats were subcutaneously induced using alloxan monohydrate at dosage $120 \mathrm{mg} \mathrm{kg}^{1}$ body weight. Three days after induction, glucose level measurement was conducted on the blood sample taken from tail vein. Rats were classified as diabetic at a minimum fasting glucose level of $200 \mathrm{mg} \mathrm{dL}^{-1}$. Supplementation was given every day at 10 am for 21 days. Blood glucose level was analyzed every 3 days. After 21 days, the rats were euthanized using chloroform. The abdominal cavities of the rats were opened, and the liver was immediately collected, washed in normal saline, and stored in 10\% neutral buffered formalin. Experiments condition was permitted by Surya University Research Institute and Community Service, Indonesia number 001.12.18.

\section{Parameters assessed}

Glycemic index level: The determination of the glycemic index was based on the research of [2] which began with the preparation of the test animals, i.e., the test animals were fasted for $10 \mathrm{~h}$ before being treated. Ten rats were used to determine the glycemic index. The first treatment is control which is given glucose solution as much as $0.15 \mathrm{~g}$, the second and third treatment is given two best analog rice formulations with a dose containing $0.15 \mathrm{~g}$ of carbohydrates available. Each treatment was given with a minimum time span of 3 days. Measurement of blood glucose levels was carried out in the span of $2 \mathrm{~h}$ at $0,15,30,60,90$, and 120 minutes. The measurement results were made in a blood glucose response curve and AUC was calculated. The glycemic index value is obtained by comparing analog AUC rice with standard glucose AUC and multiplied by 100 .

Blood glucose level analysis: Fasting glucose analysis was conducted using glucometer (Accu-ChekOे Active) on blood is taken from tail vein every three days.

Histological examination: The livers were dehydrated using alcohol series from $70 \%$ to $100 \%$ alcohol and embedded in paraffin using an embedding machine. Paraffin blocks were sectioned using a rotary ultramicrotome, distributed onto a glass slide, and dried overnight. Slides were observed under a microscope after being stained with hematoxylin and eosin dyes and mounted.

\section{Statistical analysis}

The experimental data were analyzed using one-way analysis of variance (ANOVA) (SPSS 20.0 Statistical Software Program for Windows). Significant differences among experimental values were assessed using Tukey HSD ( $\mathrm{p}<0.05)$.

\section{RESULTS}

\section{Glycemic index}

The average glucose AUC value is 3770,926 . This AUC value will be compared with the analog rice AUC value.

Giving analog rice is done by cooking rice according to the dose into porridge, then the porridge will be rounded to the same rat that has been fasted too before. The average AUC value of analog rice in the A1B1C3 formulation was 1485,753 . With this the rice glycemic index value can be calculated as follows:

$($ AUC analog rice $) /($ AUC glucose $) \times 100=1485,753 / 3770,926 \times$ $100=39,40$

While the average AUC value of analog rice formulation A4B1C3 is 1399,786 . With this the rice glycemic index value can be calculated as follows:

$($ AUC analog rice $) /($ AUC glucose $) \times 100=1399,786 / 3770,926 \times$ $100=37,12$

The analog rice glycemic index of the A1B1C3 and A4B1C3 formulations was 39.40 and 37.12 so that both rice formulations were included in the low glycemic indexed food category.

\section{Blood glucose}

Blood glucose level during 21 days in all treatment groups are presented in Table 1. Positive control (A) group had a decreasing blood glucose level of $35.66 \%$, while the negative control (B) group had an increasing blood glucose level of $15.09 \%$. A similar pattern of B group was also found in IR 64 rice (C) group, with $39.18 \%$ increasing blood glucose. While both analog rice groups (D and E) had a similar pattern in $18.97 \%$ and $25.50 \%$ decreasing blood glucose.

\section{Histological examination}

Hematoxylin and eosin (H\&E) staining of liver tissue was performed to evaluate whether the analog rice supplementation changes in the diabetic rats liver (Figure 1). The observation included necrosis and degeneration of pancreatic tissue. Cell damage in the tissue showed by empty space on islets of Langerhans. Group A had orderly islets of Langerhans and there are nuclei. Meanwhile, at Group B and $\mathrm{C}$, there are many empty spaces indicated severe damage. Group

Table 1: Characteristics of analogue rice.

\begin{tabular}{|c|c|c|c|c|c|c|c|}
\hline Formulation & $\begin{array}{l}\text { Arrowroot } \\
\text { content (\%) }\end{array}$ & $\begin{array}{c}\text { Cowpea content } \\
(\%)\end{array}$ & $\begin{array}{c}\text { Carbohydrates } \\
\text { (\%wb) }\end{array}$ & $\begin{array}{l}\text { Food Fiber } \\
\quad(\% w b)\end{array}$ & $\begin{array}{c}\text { Available } \\
\text { Carbohydrates (\%wb) }\end{array}$ & $\begin{array}{l}\text { Glycemic } \\
\text { Index }\end{array}$ & $\begin{array}{c}\text { Decrease in blood } \\
\text { sugar levels ( } 21 \text { days) }\end{array}$ \\
\hline A1B1C3 & 100 & 0 & 81,20 & 17,33 & 63,87 & 39,40 & $18,97 \%$ \\
\hline A4B1C3 & 70 & 30 & 77,32 & 21,35 & 55,97 & 37,12 & $25,50 \%$ \\
\hline
\end{tabular}


$\mathrm{D}$ and $\mathrm{E}$ still had some pancreatic beta-cell although they were not neat as Group A.

\section{DISCUSSION}

\section{Chemical properties}

Analog rice glycemic index test was carried out on test animals based on the research of [2] with a control food in the form of a glucose solution of $0.15 \mathrm{~g}$. The analog rice provided contains $0.15 \mathrm{~g}$ of available carbohydrates. Analog rice formulation A1B1C3 contains carbohydrates at $81.2039 \%$ and food fiber at $17.3297 \%$, so that the amount of carbohydrate available in analog rice at A1B1C3 formulation is $63.8742 \%$. While the analog rice formulation A4B1C3 contains $77.3224 \%$ carbohydrates and $21.3513 \%$ food fiber, so the amount of carbohydrate available in A4B1C3 analog formulation rice is $55.9712 \%$ (Figure 2).

\section{Glycemic index}

Test animals fasted for $10 \mathrm{~h}$ first, then measured fasting blood sugar levels first. Glucose as much as $0.15 \mathrm{~g}$, analog rice formulation A1B1C3 amounted to $0.23 \mathrm{~g}$, and analog rice formulation A4B1C3 amount of $0.26 \mathrm{~g}$ were dissolved in distilled water and rounded to mice. Time measurement starts after a session and is measured for 2 hours.
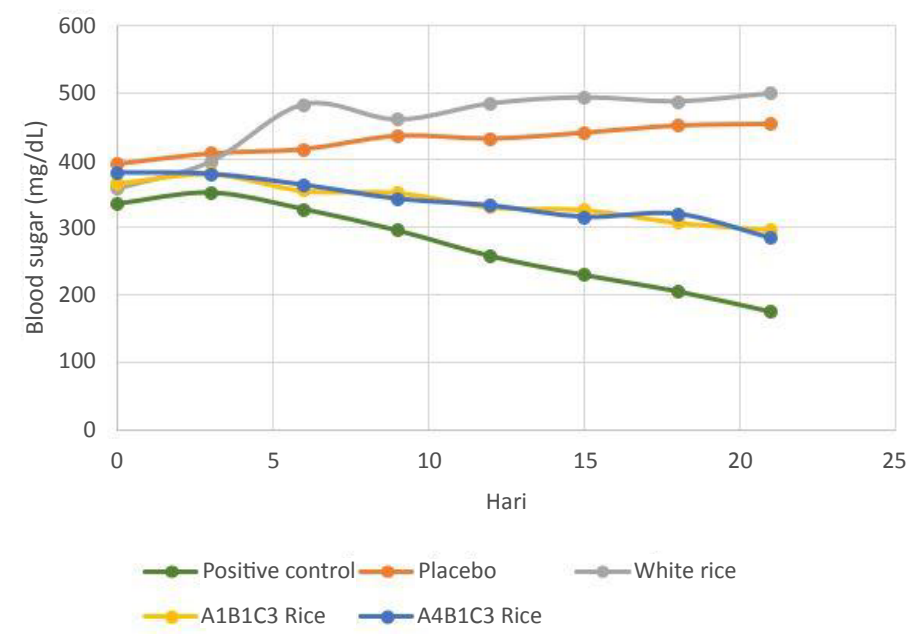

Figure 1: Changes in rat blood sugar.

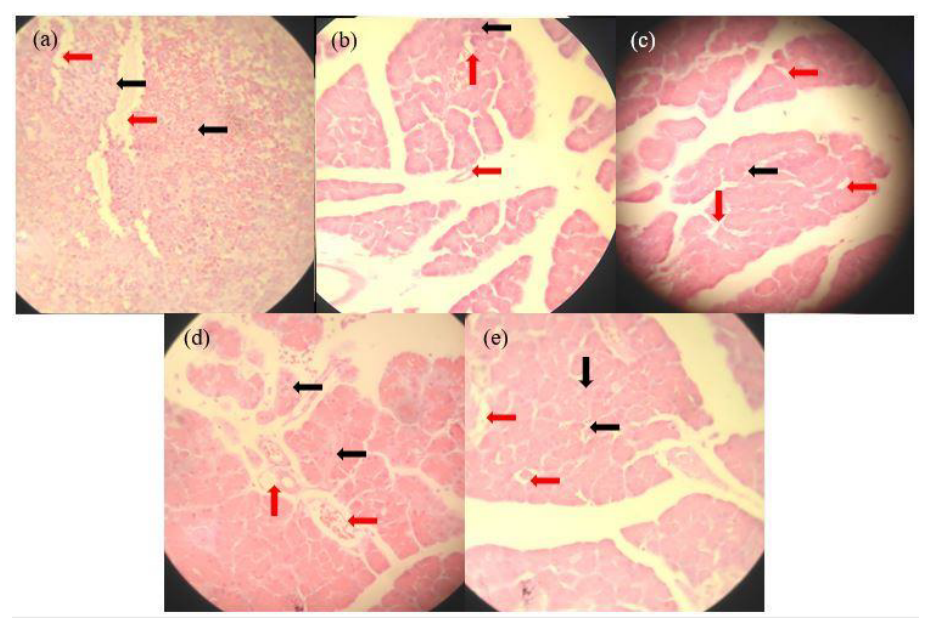

Figure 2: Pancreatic appearance 400 times magnification by hematoxylineosin staining in the positive control group (a); Placebo (b); White rice (c); Analogue rice A1B1C3 (d); Analogue rice A4B1C3 (e). Black arrows indicate beta cells and red arrows indicate empty space on the island of Langerhans.
Consumption of low glycemic indexed rice can increase insulin sensitivity and reduce the risk of disease because consumption of high glycemic indexed food has a positive correlation with the increase in the number of type 2 diabetes [3]. Low glycemic index food consumption can also reduce hypoglycemia because low glycemic index foods can reduce glycemic variability [4]. This can reduce the incidence and risk of microvascular complications associated with diabetes [5].

The glycemic index value of food is influenced by several factors, namely the composition of starch and its properties, the content of food fiber, sugar content, protein content, processing techniques, varieties, particle size, acidity, harvest time and storage time. The raw material for making analog rice in the form of arrowroot tubers and cowpea has a low glycemic index. Arrowroot tubers have a glycemic index of 14 [6] and mature cowpea has a glycemic index of 46 [7]. The increase in the value of the glycemic index when it becomes rice is caused by changes in particle size. Rice particle size is smaller than arrowroot tuber particle size which causes a large surface area that can be exposed to enzymes [8].

The analog rice formulation A4B1C3 has a lower glycemic index than the analog rice formulation A4B1C3 because the addition of legume flour to food products can reduce the glycemic index value by $18 \%$ [9]. This is due to the addition of protein from cowpea flour. Protein can form a food matrix with amylose, thus slowing the rate of emptying the stomach and reducing digestibility [10]. The protein content also increases insulin secretion and decreases postprandial blood glucose concentration. Besides, analog rice formulation A4B1C3 also has a higher content of food fiber which can reduce the glycemic index value because it slows carbohydrate digestion by forming a matrix outside the starch granules.

\section{Blood sugar levels}

Damage to the island of Langerhans is caused by the toxic effect of alloxan on the pancreas. Alloxan induced into the body of rats will experience redox reactions that produce free radicals and alloxan radicals that specifically damage pancreatic beta cells [11]. As a result of beta-cell damage, insulin cannot be produced so that mice develop diabetes characterized by hyperglycemia. This is the same principle as type 2 diabetes. While type 1 diabetes mellitus is sometimes also known as juvenile diabetes, because diabetes is generally experienced by patients under the age of 40 years. Type 1 diabetes mellitus is caused by pancreatic organs in the body unable to produce insulin. When the body cannot produce insulin, the blood sugar levels cannot be controlled and can cause damage to organs [12]. The inability of the pancreas to produce insulin is caused by autoimmune disease [13].

Insulin that is not produced by the body causes the amount of carrier protein to be very low. As a result, the process of glycogenesis and glycogenolysis is inhibited. To replace insulin, the process of glucose formation will be stimulated by glucagon and epinephrine which work through cAMP. Both of these substances have antagonistic properties to insulin. This can cause patients to experience hyperglycemia, ie glucose entering the patient's body will accumulate in blood plasma [11,12].

Increased blood sugar levels due to induction of alloxan which initiates free radicals due to redox reactions. Alloxan and its reduction product, dialuric acid, form a redox cycle with the formation of superoxide radicals and undergo dismutation to hydrogen peroxide [14]. These radicals cause beta cell oxidative 
stress, such as in patients with diabetes due to oxidative stress [13]. Alloxan can also inhibit calmodulin activity which inhibits insulin secretion [15]. Alloxan also increases the concentration of cytosolic free calcium ions in beta cells so that insulin concentrations increase very rapidly and cause impaired peripheral insulin sensitivity in a short time [16]. Hyperglycemia can exacerbate betacell damage because chronic hyperglycemia conditions tend to increase ROS through glucose metabolic pathways such as glucose autoxidation, metabolism of metiglioxal formation, and oxidative phosphorylation [13].

The positive control group was given glibenclamide at a dose of $0.45 \mathrm{mg} / \mathrm{kg}$ BW which was dissolved in $2 \mathrm{~mL} \mathrm{0.5 \%} \mathrm{CMC} \mathrm{solution.}$ Glibenclamide cannot be dissolved in water, so it is given in the form of a suspension using a CMC suspending agent. CMC cannot be digested in the digestive system of rats due to the absence of cellulase enzymes, so the use of CMC will not affect the blood glucose levels of rats [17]. Glibenclamide is a drug for people with type 2 diabetes mellitus which is included in the sulfonylurea group. Glibenclamide is used because this drug is one of the sulfonylureaderived drugs with the potential to decrease blood glucose levels higher than sulfonylureas [18].

Glibenclamide can stimulate pancreatic beta cells for the secretion of the hormone insulin so that it can reduce blood glucose, but it cannot stop autoxidation, glycation, and polyols [19]. Glibenclamide has a working period of 12-24 hours because 90$99 \%$ of glibenclamide is bound to plasma proteins. This allows the action of glibenclamide to occur gradually [17]. So that the administration of glibenclamide in the span of once a day can also have a significant effect on reducing blood sugar. Mice on positive control experienced a decrease in blood sugar by $7.55 \mathrm{mg} /$ day or by $47.37 \%$ for 21 days. Based on the T-test, the decrease occurred significantly different (significance value $<0.001$ ). Research conducted by [18] showed that the administration of glibenclamide can reduce blood sugar by $35.66 \%$ for 15 days.

The placebo group was given $0.5 \% \mathrm{CMC}$ of $4 \mathrm{~mL}$ to eliminate the effect of CMC on the experimental results [17]. Giving CMC in the placebo group was also given in the span of once a day. CMC cannot be digested and absorbed, so CMC administration should not affect blood glucose levels [18]. However, pancreatic beta-cell damage due to alloxan makes glucose metabolism from rat feed in the rat's body more difficult and can further damage pancreatic beta cells. The placebo group rats experienced an increase in blood sugar of $2.83 \mathrm{mg} /$ day or as much as $15.09 \%$ for 21 days. Based on the T-test, the increase in blood sugar for 21 days did not differ significantly (significance value=0.251).

Blood sugar levels in the white rice group increased by $6.68 \mathrm{mg} /$ day or by $39.18 \%$. Based on the T-test, the increase in blood sugar for 21 days was significantly different (significance value $=0.004$ ). This is because white rice has a high glycemic index value due to low fiber content in white rice. A rapid rise in blood sugar when the pancreatic beta cells are damaged can further worsen pancreatic beta-cell damage and the ability to metabolize blood sugar decreases.

Blood sugar levels in the A1B1C3 and A4B1C3 rice groups decreased by 3.30 and $4.63 \mathrm{mg} /$ day or by $18.97 \%$ and $25.50 \%$. This decrease is significantly different from the significance value of 0.035 and 0.024 . This decrease was due to the high content of food fiber. Food fiber can absorb water and bind glucose, thereby reducing glucose availability. Dietary fiber can also form complexes with carbohydrates and increase the viscosity of the digestive tract so that the digestibility of carbohydrates is reduced. Controlled blood sugar can reduce insulin workload [20] (Figure 3).

The A4B1C3 rice group had a greater decrease because it had higher levels of food fiber and protein. Protein is an important modulator in glucose homeostasis by increasing gluconeogenesis and preventing insulin resistance [21]. Research conducted by [22] showed a synergistic effect when people with type 2 diabetes consume glucose with protein in increasing insulin stimulation so that insulin concentration increases compared to just consuming glucose. Consumption of protein by half the amount of glucose can increase insulin concentration as much as 1.9 times. This is because the consumption of protein stimulates the concentration of glucagon which circulates in the blood [23]. The presence of protein in the intestine provides an increased response to the hormone incretin which is the main stimulus for insulin secretion [22].

Another factor that influences insulin secretion is the type of amino acid it contains [22]. Some amino acids that can increase the stimulation of insulin secretion are alanine (Ala), arginine (Arg), phenylalanine (Phe), isoleucine (Ile), leucine (Leu), and lysine (Lys). The highest amino acid in cowpea is leucine, which is $76.8 \mathrm{~g} / 16 \mathrm{~g}$ $\mathrm{N}$, followed by lysine at $61.0 \mathrm{~g} / 16 \mathrm{~g} \mathrm{~N}$, phenylalanine at $51.7 \mathrm{~g} / 16$ g N [24]. Currently, soy is a functional food for diabetics because it contains amino acids that stimulate insulin secretion. Research conducted by [25] shows that the amino acid profile that stimulates insulin secretion in cowpea is the best and most closely resembles soybeans compared to other types of local legumes.

The siege of cowpea also increases the number of amino acids. The amino acids of nuts that have been increased have increased by $14.88 \%$ [25]. Besides, the protein in bean flour is not bound by the bean matrix so that digestibility increases.

\section{Pancreatic histopathology}

The rat pancreas is located in the abdominal cavity which has a surface that forms lobulation. The pancreas of the rat is grayishwhite to reddish. The pancreas is a mixture of exocrine and endocrine. Exocrine glands in the form of serous acinus which secrete enzymes and proenzymes that break down proteins (trypsinogen and kemotripsinogen), hydrolyze fats to glycerol and

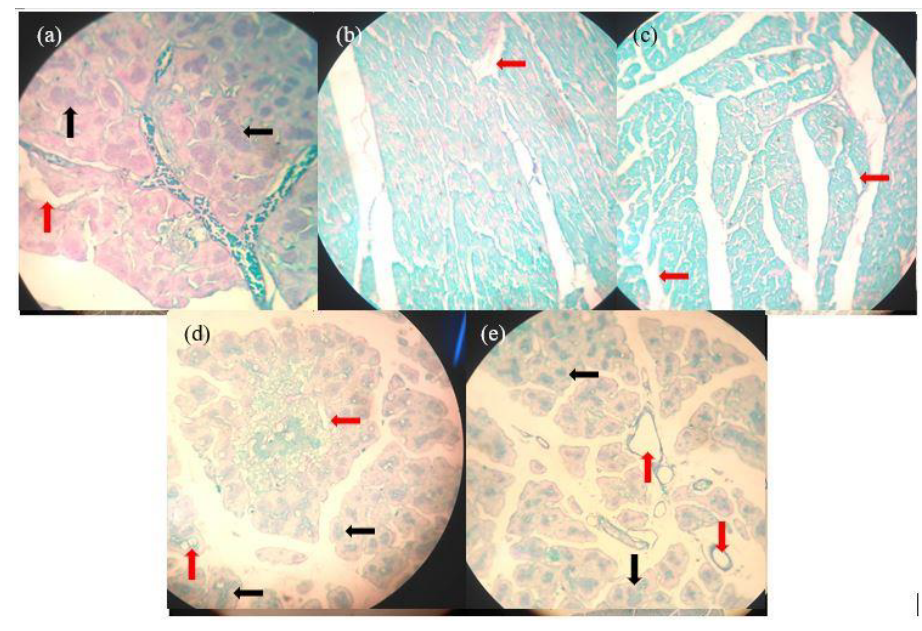

Figure 3: The cross-section of the pancreas is enlarged 400 times by immunohistochemical staining in the positive control group (a); Placebo (b); White rice (c); Analog rice A1B1C3 (d); Analog rice A4B1C3 (e). Black arrows indicate beta cells and red arrows indicate empty space on the island of Langerhans. 
fatty acids (lipases) and hydrolyze starch and fat into ribonuclease and deoxyribonuclease (amylase). Enzyme regulation is regulated by the hormones secretin and cholecystokinin produced by the duodenal mucosa and the vagus nerve. Whereas pancreatic endocrine is an island of Langerhans which appears as a group of rounds, pale cells, managed by fine hoops [26].

Pancreatic histopathology of the positive control rat group showed Langerhans is in good shape and there are still beta cells, although cell necrosis is still visible which is marked by the presence of empty space in Langerhans Island. This is because the administration of glibenclamide can stimulate the release of stored insulin and increase insulin secretion due to glucose stimulation, which also decreases glucagon levels [27]. Giving glibenclamide only improves the function of cells that produce insulin, but does not improve the shape or morphology of the island of Langerhans [28]. Giving glibenclamide effective in the early stages of diabetes, but less effective in preventing organ damage due to ROS [29].

Pancreatic histopathology of rats in the analog rice treatment group showed the presence of beta cells, although not as much as the positive control group and also the shape of the island of Langerhans which was not as good as the positive control group. However, the pancreatic profile of rats in the analog rice treatment group was better than the pancreatic profile of the placebo and white rice rats. This is because rats in the analog rice treatment group had high food fiber intake through rice supplementation. This food fiber intake inhibits the digestion and absorption of carbohydrates, decreases the absorption of glucose in the blood, and produces short-chain fatty acids [30-32]. So that rats will consume less feed and more controlled blood sugar levels. With controlled calorie intake and blood sugar levels, insulin sensitivity can increase slowly [33].

Group E has a good pancreatic profile because A4B1C3 rice has high dietary fiber and protein content. Protein is an important modulator in glucose homeostasis by increasing gluconeogenesis and preventing insulin resistance [21]. Research conducted by [22] showed a synergistic effect when people with type 2 diabetes consume glucose with protein in increasing insulin stimulation so that insulin concentration increases compared to just consuming glucose. Consumption of protein by half the amount of glucose can increase insulin concentration as much as 1.9 times. This is because consumption of protein stimulates the concentration of glucagon which circulates in the blood [23]. The presence of protein in the intestine provides an increased response to the hormone incretin which is the main stimulus for insulin secretion [22]. The amino acid profile that stimulates insulin secretion in cowpea is the best and most closely resembles soybeans compared to other types of local legumes [25].

\section{CONCLUSION}

Analog rice has a hypoglycemic effect on blood sugar levels of diabetic rats because it can reduce blood sugar levels significantly in 21 days. Analog rice formulations A1B1C3 and A4B1C3 can reduce blood sugar levels by $18.97 \%$ and $25.50 \%$ for 21 days. Decreased blood sugar in the analog rice group was significantly different from the positive control group, placebo, and white rice. Histopathological profile of the pancreatic to hematoxylin-eosin staining and immunohistochemistry in analog rice groups showed that pancreatic beta-cell regeneration occurred.

\section{ACKNOWLEDGEMENT}

This research was supported by Indofood Riset Nugraha period 2018/2019. We thank our colleagues from Indofood Riset Nugraha who provided insight and expertise that greatly assisted the research.

\section{STATEMENT OF ETHICS}

The study was approved by Surya University Research Institute and Community Service, Indonesia in November 2018-January 2019, indicated by the issuance of a certificate passing the ethical review number 001.12.18.

\section{DISCLOSURE STATEMENT}

The authors have no conflicts of interest to declare.

\section{FUNDING SOURCES}

This study was supported by a grant (2018-2019) from Indofood Riset Nugraha.

\section{REFERENCES}

1. Marsono Y. Glycemic Index of Tubers. Agritech. 2002;22:13-16.

2. Thannoun AM, Kubati AAMM. Blood Glucose Response and Glycemic Index of Diets Containing Different Sources of Carbohydrate in Healthy Rats. Mesopotamia J of Agric. 2010;38:24-34.

3. Opperman M, Venter C, Oosthuizen W, Thompson R, Vorster H. Meta-analysis of the health effects of using the glycemic index in mealplanning. Br J Nutr. 2004;92:367-381.

4. Thomas D, Elliot EJ. Low glycaemic index, or low glycaemic load, diets for diabetes mellitus. Cochrane Database Syst Rev. 2009;1.

5. Kirpitch AR, Maryniuk MD. The 3 R's of Glycemic Index: Recommendations, Research, and the Real World. Clin Diabet. 2011;29:155-159.

6. Lestari LA, Huriyati E, Marsono Y. The development of low glycemic index cookie bars from foxtail millet (Setaria italica), arrowroot (Maranta arundinacea) flour, and kidney beans (Phaseolus vulgaris). J Food Sci Technol. 2017;54:1406-1413.

7. Oboh HA, Agu K. The Effects of Various Traditional Processing Methods on The Glycemic Index and Glycemic Load of Cowpeas (Vigna unguiculata). J Food Biochem. 2010;34:1332-1342.

8. Urooj A, Puttraj S. Digestibility index and factors affecting rate of starch digestion in vitro in conventional food preparation. Nahrung. 1999;43:42-47.

9. Noviasari S, Kusnandar F, Budijanto S. Development of Analog Rice by Utilizing White Corn. Jurnal Teknologi dan Industri Pangan. 2013;24:194-200.

10.Alsaffar AA. Effect of food processing on the resistant starch content of cereals and cereals products-a review. Int J Food Sci Tech. 2011;46:455 462.

11. Campbell TC, Campbell TM. The China Study. Dallas: Benbella Books.

12.Cervin C, Lyssenko V, Bakhtadze E, Lindholm E, Nilsson P. Genetic Similarities Between Latent Autoimmune Diabetes in Adults, Type 1 Diabetes, and Type 2 Diabetes. Diabetes. 2008;57:1433-1437.

13.Patley C, Srivastava DN, Patley R, Kohli S. Alloxan Induced Oxidative Stress and Impairment of Oxidative Defense System in Rats. Asian Journal of Biomedical and Pharmaceutical Sciences, 2013;2(15):58-61. 
14. Flekel HJ. The Laboratory Rat Research Application. San Diego: Academic Press Inc., 1994:8-21.

15. Rohilla A, Ali S. Alloxan Induced Diabetes: Mechanisms and Effects. Int J Pharm Biomed Res. 2012;3:819-823.

16. Tahir IM, Akhter N, Parveen A, Mehboob H, Saleem S, Munir N, et al. Effects of methanolic and aqueous extracts of Ipomoea batatas L on mineral contents level (calcium and magnesium) in alloxan-induced diabetic rats. Pak J Pharm Sci. 2018;31:2077-2083.

17. Sari SP, Mun'im A, Fitriani SW. Effect of Noni juice (Morinda citrifolia Linn.) On Glibenclamide in Reducing Blood Glucose Levels in Male White Rats Made by Diabetes. Majalah Ilmu Kefarmasian. 2012;9:1-66.

18. Fahri C, Sutarno, Listyawati S. Glucose and Total Cholesterol Levels of Hyperglycemic Rats (Rattus norvegicus L.) Blood after Giving Meniran Root Methanol Extract (Phyllanthus niruri L.). Biofarmasi. 2005;3:1-6.

19. Rahmawati G, Rachmawati FN, Winarsi H. Superoxide Dismutase Activity of Diabetes Mice Given Cardamom and Glibenclamide Stem Extracts. Scripta Biologica. 2014;1:197-201.

20.Nurhidajah N, Nurrahman N. Hypoglycemic Effect of Brown Rice Sprouts in STZ-NA Induced Mice with Parameters of Insulin Levels, HOMA-IR Index and HOMA $\beta$. Agritech. 2016;36:433-439.

21. Ke Q, Chen C, He F, Ye Y, Bai X, Cai L, et al. Association between dietary protein intake and type 2 diabetes varies by dietary pattern. Diabetol Metab Syndr. 2018;10.

22.Gannon MC, Nuttall FQ, Neil BJ, Westphal SA. The insulin and glucose responses to meals of glucose plus various proteins in type II diabetic subjects. Metabolism. 1988;37:1081-1088.

23.Nuttall FQ, Mooradian AD, Gannon MC, Billington C, Krezowski P. Effect of Protein Ingestion on The Glucose and Insulin Response to a Standardized Oral Glucose Load. Diabetes Care. 1984;7:465-470.
24.Utomo JS, Antarlina SS. Processing Technology and Cowpea Products. Monograf Balitkabi. 1998;3:120-138.

25.Kanetro B, Setyowati A. Amino Acid Profile Stimulating Insulin Secretion in Extracts After Protein Separation of Local Bean Sprouts. Agritech. 2013;33:258-264.

26. Mycek MJ, Harvey RA, Champe PC. Insulin and Oral Hypoglycemic Drugs. Edisi 2. Jakarta: Widya Medika. 2011.

27. Dewanti T, Wijayanti N, Handayani D, Rochmawati N. Hypoglycemic Effect of Black Grass Jelly Extract (Mesona palustris BL) in Diabetes Wistar Mice Induced by Alloxan. Jurnal Kedokteran Brawijaya, 2015;28:202-207.

28. Bintari IG. Detection of Aeromonas hydrophila in Kidney Mice (Mus musculus) with Immunohistochemical Techniques. Undergraduate dissertation. Airlangga University, 2016.

29. Cook MN, Girman CJ, Stein PP, Alexander CM, Holman RR. Glycemic Control Continues to Deteriorate After Sulfonylureas are Added to Metformin among Patients with Type 2 Diabetes. Diabetes Care. 2005;28:995-1000.

30.Fuiji H, Iwase M, Ohkuma T, Ogata-Kaizu S, Ide H, Kikuchi Y, et al. Impact of dietary fiber intake on glycemic control, cardiovascular risk factors and chronic kidney disease in Japanese patients with type 2 diabetes mellitus: the Fukuoka Diabetes Registry. Nutr J. 2013;12:1-8.

31. Maulida D, Estiasih T. Hypoglycemic Effects of Polysaccharides WaterSoluble Gadung Bulbs (Dioscorea hispida) and Alginates: Literature Review. Jurnal Pangan dan Agroindustri. 2014;2:136-140.

32.Saputro PS, Estiasih T. Effect of Water Soluble Polysaccharides (PLA) and Tuber Food Fiber on Blood Glucose: Literature Review. Jurnal Pangan dan Agroindustri. 2015;3:756-762.

33.Ku M, Ramos MJ, Fung J. Therapeutic fasting as a potential effective treatment for type 2 diabetes: A 4-month case study. J Insul Resist. $2017 ; 2: 1-5$ 